This item was submitted to Loughborough's Research Repository by the author.

Items in Figshare are protected by copyright, with all rights reserved, unless otherwise indicated.

\title{
Indexicality and (im)politeness
}

PLEASE CITE THE PUBLISHED VERSION

http://www.palgrave.com/gb/book/9781137375070

PUBLISHER

(c) Palgrave Macmillan

VERSION

AM (Accepted Manuscript)

PUBLISHER STATEMENT

This book chapter was published in the book The Palgrave Handbook of Linguistic (Im)politeness. The definitive published version is available at https://doi.org/10.1057/978-1-137-37508-7.

\section{LICENCE}

CC BY-NC-ND 4.0

\section{REPOSITORY RECORD}

Pizziconi, Barbara, and Christine Christie. 2017. "Indexicality and (im)politeness". Loughborough University. https://hdl.handle.net/2134/24619. 


\title{
Indexicality and (im)politeness
}

\author{
Barbara Pizziconi and Chris Christie
}

\section{Introducing Indexicality and (Im)politeness}

As an introduction to the type of analysis that an indexical approach to language entails, let us consider the following exchange.

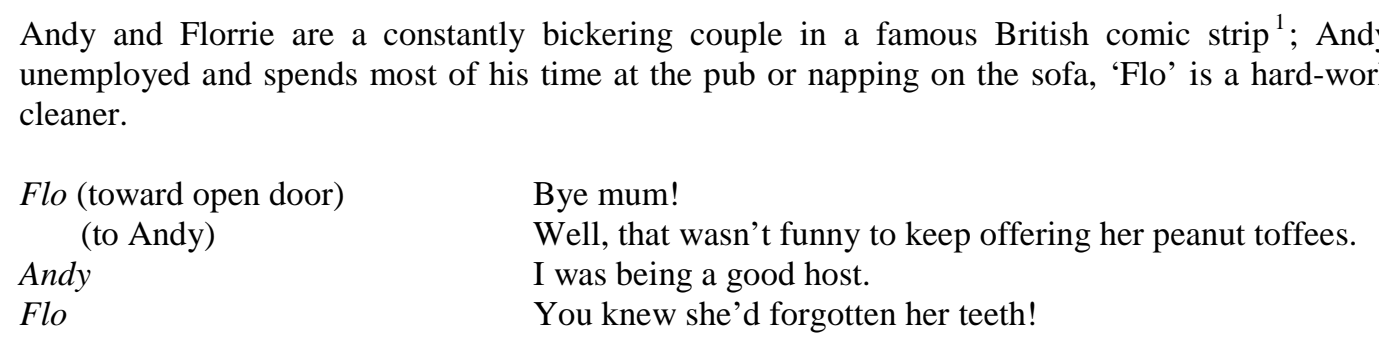

If we were to adopt Leech's (1983, p. 104) framework, we might argue that the exchange contains an instance of the speech act of 'criticism', and we might categorise it as a conflictive kind of act. And if we were adopting Brown and Levinson's (1978 [1987]) framework we might categorise this as a threat to the hearer's positive face. Beyond the identification of 'face-threatening acts' and 'impoliteness', however, other important aspects of the interaction could be scrutinized. For example, we could investigate the transparency of the criticism, i.e. the degree to which the formula 'that wasn't funny', is recognized as meaningful across social groups, investigating what 'type' of people use it, with which addressees and in which social contexts it is likely to occur; or in which registers it is likely to interact with other (co-occurring) signs. We could explore how each sign contributes to the overall effect. For example the deictic 'that' in Flo's first turn, which, though not obviously or conventionally associated with criticism, might be seen to reinforce the criticism if it was categorized as a marker of empathetic distancing (Levinson, 1983, p. 81; Lyons, 1977, p. 677). We could also speculate about a possible hidden agenda in Flo's utterance, effectively a self-positioning act, through which she projects herself as a ‘considerate/caring’ person. Through Andy’s retort, i.e. his laying

\footnotetext{
1 Source: http://chesscomicsandcrosswords.blogspot.co.uk/2011/07/andy-capp-and-hagar-horrible-andtheir.html [Accessed on 14 November, 2015].
} 
claims to a recognisable (typified) persona, we could explore an arguably common-sense (normative) etiquette regulating polite conduct (e.g. the good host makes sure guests are offered a reasonable supply of treats). We could account for the humorous effect of the cartoon by recourse to the socially recognisable 'script' whereby the relation between mothers-in-law and sons-in-law is typically thorny. Some knowledge of the troubled history of the exchanges between these particular participants would additionally explain Flo's frustration with Andy (graphically rendered, in the last box of the strip, through her body language and facial expression, i.e. other semiotic systems interacting with language). We could examine the strip in the context of 'mother-in-law jokes', premised on particular a particular set of stereotypifications that derive from misogynistic ideologies of age and gender that give this particular cartoon its meaning, explore notions of sexism and interrogate its morality.

The terms in italics in the commentary above point to issues and questions raised by scholarship on indexicality which we articulate in the next section. Some of these have been addressed in recent (im)politeness studies, thanks to felicitous contaminations from other disciplines (as we note in section 3). Our overall aim in this chapter, however, is to demonstrate that considerations of this kind are the object of enhanced and systematic attention in an indexical approach to language (and particularly to the language of social relations) and to sketch out how they might contribute to the study of linguistic (im)politeness.

\section{Indexicality}

The development of indexicality as an analytical tool that is of interest to work in (im)politeness can be traced back to Charles Sanders Peirce's distinction between signs as icons, indices and symbols, depending on the kind of relation they encompass with some object. Peirce distinguishes indices from other signs in these terms:

\footnotetext{
"An index stands for its object by virtue of a real connection with it, or because it forces the mind to attend to that object. Thus, we say a low barometer with a moist air is an indication of rain; that is, we suppose that the forces of nature establish a probable connection between the low barometer with moist air and coming rain.” (Peirce, 1998 [1895], Ch.3, p. 14)
} 
Psychologically, the action of indices depends upon association by contiguity and not upon association by resemblance [icons, a.n.] or upon intellectual operations [symbols, a.n.]” (Peirce, 1901, p. 531).

Scholarship that has developed Peirce's notion of indexicality has produced a substantial body of research with different traditions. One is represented by works in semiotics, logic and philosophy of language and articulates a theory of the mechanisms whereby indexical forms achieve reference ${ }^{2}$; another, represented in social semiotics, linguistic and sociocultural anthropology (e.g. Ochs, 1993, 1996; Agha, 2007; Hanks, 2000, 2009; Silverstein, 2003, 2010), articulates what these indexical properties entail for the construction of social meanings, which is more closely relevant to the study of linguistic (im)politeness.

Indexicality is not unique to language, but a general property of semiotic systems (barometers point to weather conditions, weathervanes to wind direction). When the concept is applied to language, it is used to refer to the capacity of linguistic signs of various kinds to 'invoke' some other object, while not explicitly describing or referring to it. An engagement with indexicality therefore calls for some focused attention to a sign, but also allows for different interpretations of that sign, which depend on the contextual conditions of utterance. Such conditions include not only the time or location of the utterance, but also many other norms of interpretation specific to local contexts, which contribute to the definition of the type of activity under way. To the extent that language mediates social activities, the study of indexicality therefore demands a study of the social processes that create and regulate them.

\subsection{Indexicality as the study of deixis}

Lyons (1977) highlights two different senses in which Peirce used the term 'index' and which his followers elaborated on: the first is as "signs that reveal personal characteristics of the writer or speaker" (and hence fall into the province of 'stylistics', Lyons, 1977, p. 106-107), the second as signs whose meaning varies from one occasion of utterance to another, as they are context-dependent. The latter - deictics - have received much attention in pragmatics, and several 'types' are commonly discussed: time, space, person, discourse and social deictics (e.g. Levinson, 1983; cf. also the seminal treatise by Fillmore, 1977).

\footnotetext{
${ }^{2}$ We do not appraise this here but see Ponzio 2006 for reviews of Buhler, Jakobson, Sebeok; Lyons, 1977, p. 106 for Abercrombie or Bar-Hillel.
} 
Deictics have specific properties, which are able to 'organize' (i.e. structure) the context, anchoring perceived objects (referents) to a centre radiating from the speaker's self and mapping out their positions in relation to that centre. Spatial deixis, for example, is traditionally conceptualized as a principle for organizing physical space based on the parameter of "proximity" (of an object to self).

Among the many types of deixis discussed in the literature social deixis is most obviously relevant to (im)politeness. Levinson (2004, p. 119) defines social deixis as that which "involves the marking of social relationships in linguistic expressions, with direct or oblique reference to the social status or role of $x$ ". Social deictics have been seen as a metaphorical transposition from a physical space (Shibatani, 1990, p. 374; Hiraga, 1999; Marmaridou, 2000), and as signs that organize social space on the basis of (culturally salient) parameters such as the status or role of an individual (e.g. superior or subordinate), or the nature of the relationship between individuals (e.g. intimate or distant). Classic examples of social deictics are the distinctions between $\mathrm{T} / \mathrm{V}$ personal pronouns in European languages ${ }^{3}$, or the far richer repertoires of some Asian languages, in which comparable distinctions are observable not only in (generally larger stocks of) personal pronouns, but also nouns, predicates, adverbs, etc. (cf. e.g. Errington, 1988 for Javanese Indonesian; Pizziconi, 2011 for Japanese; Brown, 2011 for Korean).

Levinson's early work distinguishes the study of social deixis from that of other sociolinguistic matters, on the grounds that the former concerns itself with the study of grammaticalization (“or encoding in language structure of social information”, 1983, p. 93) and the latter a study of language use. This distinction is however not unproblematic (see Pizziconi, forthcoming for a discussion), for two reasons. First, it limits the range of phenomena considered in examinations of (im)politeness to a relatively closed set of conventionalised forms, and secondly, it may suggest that grammaticalized markers can index objective, if symbolic, realities, and that their interpretation is socially uncontroversial. However, to the extent that the interpretation of a deictic form depends on the subjective value attributed to it on the part of speakers who may be variably acquainted with that form and/or who may interpret it through different 'ideological' filters, variability is likely to be observed as much as in other sociolinguistic phenomena. When it comes to

\footnotetext{
${ }^{3}$ Note that Silverstein $(1976$, p. 31, 38) considers deferential pronouns as pragmatic metaphors borrowing from the referential categories of 'person' and 'number', and distinguishes them from "distinct indexical expression of social deference with unique formal signals”.
} 
the symbolic and ideological reality of social matters, variability is likely to be the norm rather than the exception.

In the following section we summarise one perspective that sets out to explain the statement that 'deictics organize context' by looking at the mechanisms that appear to enable this, i.e. the interpretive categories specified by various deictic forms, which guide the identification of referents. We also elaborate further on the question of variability in sections 2.3 and 4.

\subsection{Schema of interpretation}

A description of the functional properties of indexicals, and in particular of their social function, requires a description of their modes of signification. A seminal paper by Silverstein argues that attention to these mechanisms allows us "to describe the real linkage of language to culture, and perhaps the most important aspect of the 'meaning' of speech" (Silverstein, 1976, p. 12). The challenge in the description of these mechanisms lies in the fact that several layers of "meaning” appear to be conflated in individual indexical forms. Agha's work (e.g. 2007) provides the most full-fledged and systematic discussion of such composite meanings. Deictic forms provide 'schema' of interpretation (2007, p. 46), or a “sketch of referent”, which therefore 'organizes' context but needs context for their (situated) meaning to be 'fleshed out'. This context-dependence is beautifully illustrated by Fillmore's (1971, p. 39) example of the impossibility of interpretation in an extremely poor context, e.g. a note contained in a bottle floating in the ocean which reads: "meet me here at noon tomorrow with a stick about this big” (italics added).

\begin{tabular}{|c|c|c|c|c|c|}
\hline & & $\begin{array}{l}\text { deictic } \\
\text { form }\end{array}$ & denotational schema & interactional schema & $\begin{array}{l}\text { interpersonal } \\
\text { schema }\end{array}$ \\
\hline \multirow[t]{3}{*}{ English } & $\mathrm{a}$ & I & [+ human] [ \pm subject-of-verb] & $\mathrm{S}$ of $\mathrm{E}^{\mathrm{S}}$ & \\
\hline & $\mathrm{b}$ & this/that & [+thing] [+adnominal] & proximal/distal to $\mathrm{E}^{\mathrm{S}}$ & \\
\hline & C & now/then & [+time] [+adverbial] & proximal/distal to $\mathrm{E}^{\mathrm{S}}$ & \\
\hline \multirow[t]{2}{*}{ Japanese } & $a^{\prime}$ & boku & [+ human] [ \pm subject-of-verb] & $\mathrm{S}$ of $\mathrm{E}^{\mathrm{S}}$ & $\begin{array}{l}\text { [non-formal, } \\
\text { intimate] }\end{array}$ \\
\hline & a” & watakushi & [+ human] [ \pm subject-of-verb] & $S$ of $E^{S}$ & $\begin{array}{l}\text { [humble, } \\
\text { formal] }\end{array}$ \\
\hline
\end{tabular}




\begin{tabular}{|c|c|c|c|c|}
\hline$b^{\prime}$ & $\begin{array}{l}\text { kore/sore/ } \\
\text { are }\end{array}$ & [+thing] [+adnominal] & $\begin{array}{l}\text { proximal/medial/distal to } \\
\left.\mathrm{E}^{\mathrm{S}} \text { (distal to } \mathrm{S}\right) /(\text { distal to } \\
\text { both } \mathrm{S} \text { and } \mathrm{A} \text { ) }\end{array}$ & \\
\hline$c^{\prime}$ & ima/ato & [+time] [+adverbial] & proximal/distal to $\mathrm{E}^{\mathrm{S}}$ & [non-formal] \\
\hline$c ”$ & $\begin{array}{l}\text { genzai/ } \\
\text { nochihodo }\end{array}$ & [+time] [+adverbial] & proximal/distal to $\mathrm{E}^{\mathrm{S}}$ & [formal] \\
\hline
\end{tabular}

Table 1: Schema for some deictic forms in English and Japanese (adapted from Agha 2007, p. 47 for English). [E: "speech event, current utterance(-event)", S: speaker, A: addressee,]

The person deictic $I$, for example, provides first of all a model of its denotational value, which in this case indicates a semantic trait ('human') as well as a semantic role in the proposition (here the role of 'subject' of the proposition). Together with this, it also provides a model of its interactional value. That is, it identifies which (participant) role that entity ('human') plays in the speech event (in this case 'the person who occupies the role of utterance Subject). The 'corresponding' Japanese terms (in a' and a”) are partially comparable, at least in terms of denotational and interactional schema. However they additionally provide information of a third kind, commonly referred to in discussions of honorific register (here: ‘ \pm intimate’, \pm humble’, etc.). This third category therefore provides a sketch of the interpersonal relationship between participants.

Spatial deictic forms like this/that, while comparable to the Japanese terms in b' in relation to their denotation values, differ in relation to the interactional sketch they can index, as the space or region distinction they mark ('proximal' or 'distal') is 'cut out' in less detail than in Japanese. Finally, time deictic forms like now/then are also comparable to the Japanese terms in c' and c" with regards to denotational and interactional schema, but the latter additionally convey information (' \pm formal') which can contribute to a schema of interpersonal relationship. It is important to note here the various realizations under the category of 'interpersonal schema' (' \pm intimate', ' \pm formal', etc.); these are to be understood as variations of, perhaps, a metaphorical source notion of DISTANCE (as noted in 2.1). Regardless of the particular gloss, to the extent that, for example, the indexing of formality can require observation of etiquette norms which involve the marking of mutual social positioning (e.g. status), it can be said to provide a sketch of social deixis (i.e. it schematizes the social relationship between participants to the speech event indexically, without describing it explicitly). 
From this perspective, deictic forms thus provide schema of interpretation, and sketch out denotational and interactional information; they are performative, or constitutive, in character as they do not merely reflect objective realities (although language socialization can result in a certain degree of uniformity in the way they are conceptualized within certain social groups) but can evoke such dimensions such as time, space or 'social' space (e.g. deference entitlements, or rank), and configurate them. Different configurations are evident in different languages, as we saw for English/Japanese spatial deictics, even when the categorial parameters involved are comparable. In this 'structuring' sense, deixis can be seen as one of several "resources for thinking and acting with language” (Hanks, 2000, p. 21)

While the existence of differently schematized configurations appears uncontroversial when we describe deictics in different languages (see Hanks 2009, p. 11 for a list of works on various languages), the same point can be made about "all linguistic categories, [...which are] categories-for a particular social domain of language users (a sociohistorical population of users)” (Agha, 2007, p. 47). This qualification accounts for the documented variability in the interpretation of such forms within social groups - as we discuss further in the next section. Uses of the English pronoun "we", for example, show that while in some cases - e.g. a face-to-face interaction in which the speaker refers to him/herself and at least another person - its interpretation would be highly congruent between a speaker and his/her addressee, in some others - say, when used as a "royal we" or pluralis majestatis - the successful identification of its referent is dependant on the hearer's ability (linguistic knowledge of this usage) or willingness (assumptions about its legitimacy) to read the pronoun as a first person, singular pronoun (plus some residual effects).

\subsection{Indexicality as a social process}

Silverstein's work on indexicality has stimulated a field of scholarship that theorises indexicality as a culturally situated process by which linguistic (and other semiotic) resources acquire social meaning through the contexts in which those resources typically occur (for a detailed discussion, see Blommaert, 2007 and Eckert, 2008). The model, which Silverstein describes as bringing "theorized order to a large number of what once appeared to be disparate phenomena” (2003, p. 194) has fed into a paradigm shift in 
variation studies, leading to the conceptualization of linguistic forms as resources whose social meanings are ideologically generated and are therefore not precise or fixed.

According to Silverstein (2003), social actors use language in ways that presuppose some reflexive model of an on-going activity. They choose linguistic resources they consider appropriate for that activity, based on their own assumptions about how people in certain social roles speak in those contexts, i.e. based on their notions of register. For example, an individual will speak like a teacher in a classroom, like a mother at home, or like a stranger to someone they meet in the street ${ }^{4}$. Notably, our notions of register do not apply to individual linguistic forms ${ }^{5}$, but generally to configurations of forms that tend to co-occur. This is evident in speakers' sensitivity to violations of anticipated cooccurrence. Perceptions of regularity, coherence and stability in registers are observable at all linguistic levels, be that phonological (for example 'posh' accents), morphological, lexical or syntactic, but also across verbal and non-verbal channels (e.g. the body language or the attire of people with 'posh' accents). Register models, however, based as they are on idiosyncratic communicative experiences which are never entirely replicable across individuals, are probabilistic rather than categorical, and they are subjectively flavoured: they represent linguistic ideologies. Note that notions of linguistic ideologies, or "sets of beliefs about language articulated by users as rationalization or justification of perceived language structure and use” (Silverstein 1979:193, quoted in Woolard 1998, p. 6; see also Kienpointner and Stopfner, this volume) do not pertain to language alone. "Rather, they envision and enact ties to identity, to aesthetics, to morality, and to epistemology" (Woolard 1998, p. 3) ${ }^{6}$. A register is one such ideology, providing a recognisable model of the linguistic behaviour considered to be "typical of" or "appropriate to" particular contexts of usage, of particular kinds of speakers. Silverstein $(1998,2003)$ uses the term indexical order to refer to the patterned associations observed in the linguistic forms which participate to specific registers.

Indexicals of deference-and-demeanor and honorific registers are good examples of indexical orders (Silverstein 1998, p. 131). Honorific forms which are perceived to denote

\footnotetext{
${ }^{4}$ Irvine's 'style' is similar to what has been presented here as register, and characterized as a 'social semiotic of distinctiveness' (generated when a style, and the social meanings signified by that style, contrast with other styles, and their associated social meanings), which is ideologically mediated.

5 It is possible, however, that some forms may appear to contain enough information to do this characterizing job alone (cf. the rich associations a mere interjection like "oi!" can generate in British English).

${ }^{6}$ Woolard (1998, p. 6) points out that in recent theory, arguably of particular relevance to (im)politeness, ideology is "not necessarily conscious, deliberate or systematically organized thought, or even thought at all; it is behavioural, practical, prereflective and structural".
} 
specific addressees or referents (first-order indexicality) commonly generate an additional layer of meaning (second-order indexicality), when they also come to be seen as emblematic of speaker features, e.g. properness, sophistication, education ${ }^{7}$. Further orders of indexicality can be produced by reiterative processes, if the precedent order achieves sufficient stability. Thus a second-order meaning may potentially be re-deployed, through ideologically informed characterizations of gender (e.g. stereotypifications of 'feminine' speech) or social class (e.g. upper class), generating $\mathrm{n}^{\text {th }}$ orders of indexicality. Because such developments are ideologically driven, we can expect them to delineate complex patterns of variation across and within social groups ${ }^{8}$.

Observing indexicality in language means to recognise that all linguistic forms have the potential to index a range of different social meanings. This range represents "an indexical field, or constellation of ideological meanings, any one of which can be activated in the situated use of the variable" (Eckert, 2008, p. 454). This is evident despite the fact that any given form appears to trigger relatively consistent characterizations (i.e. be linked to assumptions about the behaviour of typical social personae) or typical interactional effects. We can see this particularly clearly in folk rationalizations of the meaning of honorific forms, stereotypically construed in both lay and scholarly discourse as indexing 'deference' but in reality enabling the expression of a far broader range of interactional meanings (see for example Agha, 2007; Pizziconi, 2011). This variability occurs because, once established, a first-order form-meaning association is open to a cultural re-evaluation and can be reinterpreted in a second (third, $\mathrm{n}^{\text {th }}$ ) order of usage. Hence - despite perceptions of stability - indexical orders are never entirely settled.

In studies on indexicality the relation between language and social categories is formulated as dynamic, multidirectional, and complex. Rather than assuming simplistic and direct correlations of specific linguistic features with certain social identities, Elinor Ochs proposes that such signs index instead socially characterised acts, activities and stances, which are then recognised as typical of certain social identities. For example, an

\footnotetext{
${ }^{7}$ Notably, the development of additional indexical orders over the course of historical processes are discussed - though naturally with different terminology - in Brown and Gilman's (1960) work on terms of address (ToA), or second person singular (non-honorific) vs. plural (honorific) pronouns. This work looked not only at the reconfiguration of deictic categories of honorification targets but insightfully linked these to concomitant ideological and social changes, and additionally noted how such reconfigurations (the universal $\mathrm{T}$ in the Plain Speech of Quakers, in Communist Yugoslavia, etc.) trigger important social controversies and personal dilemma.

${ }^{8}$ While variation studies brought to the fore questions about the relation between linguistic forms and the social characteristics of speakers, the main contribution of indexicality studies to the conceptualization of linguistic variables is seen by some to be in the "ideological embedding of the process by which the link between form and meaning is made and remade” (Eckert, 2008, p. 463, emphasis added).
} 
imperative form directly indexes the act of ordering in English; respect vocabulary indexes the activity of oratory in Samoan. These acts and activities may then be associated with stances and social roles. For example, an act of assertion might index a specific epistemic stance (of certainty of knowledge) and this, in conjunction with other acts and stances, might index a specific role: "one might display the stances of knowledgeability, objectivity and care to build a certain kind of medical professional identity” (Ochs, 1996, p. 424). In addition, acts, stances and activities may be associated with 'speaking like a man' or 'speaking like a woman', according to culturally specific normative models of behaviour (Ochs, 1993, p. 151), and will also positively constitute such identities (rather then merely reflect them). Together with the constitutive function of indexical signs, another important feature further pointed out by Ochs is their 'non-exclusivity': very few linguistic forms index gender, or even the sex of speakers/addressees/referents categorically (e.g. as some kinship terms do); in most cases, this relation is distributional and probabilistic (Ochs, 1993, p. 149). This means that while variable forms of language are used by/with/for both sexes, they will be used more or less frequently by one particular social group, and can therefore 'suggest' gender based on local models of 'typical gendered conduct'.

Social categories, such as gender or class, or social values, such as deference or intimacy, are recognised, reproduced, or challenged through users' reflective awareness of linguistic indexicality and indexical orders. But the notion of “order” must be appreciated in another sense too, operating on a higher plane. Indexical orders of various kinds coexist in a broader semiotic habitat,

\footnotetext{
"a stratified general repertoire, in which particular indexical orders relate to others in relations of mutual valuation - higher/lower, better/worse. [...] That means that such systemic patterns of indexicality are also systemic patterns of authority, of control and evaluation, and hence of inclusion and exclusion by real or perceived others. That also means that every register is susceptible to a politics of access.” (Blommaert 2007, p. 117).
}

Evidence of ordered associations is commonly observable through metapragmatic activity (Silverstein, 2003, p. 203; p. 242; Verschueren, 2000; Hanks, 2009, p. 18). In particular, folk-metapragmatics (lay rationalisations of indexicality) provides evidence of ideologies through charted attributions of cultural values to patterns of linguistic behaviour. For Agha (2003, p. 242), to say that such behaviours "have cultural values associated with them is simply to say that certain regularities of evaluative behaviour can be observed and documented as data”. Agha articulates a key tenet of indexicality theory here, one that - as we show below - has important methodological consequences for indexical approaches to (im)politeness behaviour. Since “socially locatable” persons (2003, p. 242) inhabit 
positions of interest, through the observation and documentation of evaluations carried out by specific social groups or individuals, the analyst can avoid essentialist attributions of meaning and instead bring into view (and justify) different cultural values attributed to specific linguistic resources.

In the preceding sections we have charted the scope of the indexical approach from accounts that analyse the workings of linguistic forms to the implications of this view for sociolinguistic, politically sensitive, analyses of language use. In the next section we consider some of the ways in which problematic issues in politeness research might be resolved by the adoption of an indexical approach, and in section 4, we critically evaluate the way in which indexical approaches have been applied in this field.

\section{3. (Im)politeness}

As a linguistic phenomenon with obvious social reflexes, (im)politeness has been approached from many and diverse perspectives within linguistic research with an interest in context and sociocultural matters, such as sociolinguistics, pragmatics, ethnography of speaking, discourse and conversation analysis, social cognition, language acquisition, etc. (for reviews see: Sifianou, 2010; Locher, 2012). Early studies focused on 'polite’ linguistic structures and were premised on a relatively narrow conceptualization of politeness. Examples of these would be classic works on modals or speech acts (Lakoff 1973, Leech 1983) in Western languages, or sets of honorific markers in Asian languages (e.g. Martin 1964), up to Brown and Levinson’s (1978 [1987]) wide-ranging analysis of (mostly sentence-level) putatively universal strategies. These mostly linked politeness phenomena to presupposed macro-sociological variables, such as gender, age, or in/out-groupness. More recent approaches problematize such categories, no longer seeing them as independent variables but types of social meanings actively and creatively constructed through language: the 'performative' function of linguistic forms that has been noted in the theorizations of indexicality cited above. The shift in interest toward authentic types of texts, e.g. conversations stretching over multiple turns, as well as descriptions of actual, situated, contexts (the 'discursive approach' to (im)politeness, e.g. Watts, 2003; Locher, 2004; Mills, 2003, 2011) have enriched the appreciation of the diffuse quality and jointly constructed nature of (im)polite effects, including effects inherited from the preceding histories of encounters. These new interests in (im)politeness scholarship resonate with the interest, in indexicality theory, in how meaning emerges from co-textual interactions rather than being coded in individual linguistic forms (not even in arguably dedicated forms such 
as markers of 'social deixis', as noted in 2.1), and how it develops from historically traceable trajectories of development, involving chains of encounters and the constantly evolving metapragmatic discourses surrounding them (Agha, 2007, p 69-71).

An important debate opened by Watts et al. (1992) and developed in Eelen (2001) and Watts (2003) pointed out a crucial epistemological distinction between politeness as a commonsense notion that speakers develop in the course of socialization and participation in social practices (politeness ${ }^{1}$ ) and as a scientific construct (politeness ${ }^{2}$ ). While the latter aimed at providing theoretically informed generalizations (especially by those with an interest in universal pragmatic principles), the former refers to participants' uses of evaluative, and argumentative (Eelen, 2001) terms like "polite”, “rude”, etc. informed instead by personal social agendas. It was observed that the two do not invariably correspond, and that unless scientific analyses adopt participants' lay and emic perspectives (i.e. the meanings users generate and discern in authentic, pragmatically rich, historically situated contexts), scientific politeness definitions risk to misfire, finding politeness where users perceive none, and attributing polite or impolite meanings to linguistic forms or strategies - e.g. imperatives, indirect speech acts, honorific markers which in actual contexts can generate very different, sometimes inverse effects.

Locher and Watts 2005:14-16 make this point by considering the following contrasting utterances:

a) Lend me your pen.

b) Could you lend me your pen?

They maintain that while a theoretical discussion of politeness ${ }^{2}$ would argue that $b$ ) will be perceived as more polite than a) (because of the indirect formulation of the request), in actual contexts of use a speaker may consider b) simply appropriate, and not conveying any particular polite effect. Conversely, a) may be perceived as direct, but not necessarily impolite. We could moreover note that these forms may be appreciated differently (or be differently valorized) by different "types" of interactants, some commonly favouring a) and some b) for the same requestive act in the same context, depending on their (ideological) model of appropriate register ${ }^{9}$.

The 'classic' (im)politeness frameworks - Lakoff (1973), Brown and Levinson (1987 [1978]), and Leech (1983) - conceptualized politeness as departures from the CP’s

\footnotetext{
${ }^{9}$ An example of this are the different valorizations of T/V pronouns in Europe (Brown and Gilman, 1960, p. 257) up to the nineteenth century, where $\mathrm{V}$ is the reciprocal term of address for nobility and bourgeoisie, including family members, but $\mathrm{T}$ the reciprocal term of address for servants and peasantry (i.e. the pronoun's valorization is dependent on social-class membership). Cf. a similar note by Silverstein (1998, p. 142).
} 
rational efficiency. These frameworks maintain, by and large, that regardless of whether politeness-related meanings are evoked by means of specific markers (e.g. formulae, honorific terms, mitigators) or linguistic 'strategies', meaning interpretation is based on inferential processes, i.e. the contextual resolution of the implicatures generated by the (motivated) disregard of one or the other of the CP's maxims. ${ }^{10}$. As frameworks that attempted to account more comprehensively for pragmatic competence, their interest in an extralinguistic context, understood as the social conditions of language use, is indisputable ${ }^{11}$. Nevertheless, the contexts envisaged by these frameworks were not fully 'social', but reduced instead to minimal and abstract parameters; this prevents the analysis of the wealth of social facts they allegedly pattern, including the variable, often disputed, evaluations of acts of behaviours, not only across different cultures but also cultureinternally. Acknowledging indexicality in language therefore requires the adoption of disciplinary approaches and methodologies able to articulate the significance of the very authentic social contexts in which (im)politeness lives.

More recent (im)politeness theorizations have increasingly problematized such implicit homogenizing assumptions regarding culture-wide patterns, and have attempted to produce much 'thicker' descriptions of (im)politeness. These take into account the existence of normative patterns but at the same time acknowledge alternative ones (coexisting at any one time) and explore their mutual relations. Specifically, these approaches (a) recognize that users' formulations of such norms may be distinct from actual behaviour, and they therefore explore the social motivations for such inconsistencies, and (b) bring into view the multifunctionality of utterances in order to explore the multiple, parallel, expressive effects that users exploit in order to carry out, among other things, some form of social positioning. In order to reduce the inevitable essentialism of culture-wide generalizations, researchers try to tie accounts of regularities to specific frames (Terkourafi, 2005, p. 247; Locher and Watts 2008, p. 78) or to specific and contained Communities of Practice, fleeting as these may be (e.g. the papers in part II of Bargiela-Chiappini and Kádár, 2011; Mills, 2003, 2005; Graham, 2007). They also discuss identities - often the multiple ones that individuals inhabit at any one time - rather than stylized 'roles' or macrosociological categories such as gender or age, and understand

\footnotetext{
10 See Terkourafi, 2005 and Christie, 2007 for a discussion.

11 This is already evident in Lakoff's (1973:298) pioneering proposal to pair "Rules of Politeness" with the Gricean "Rules for Clarity", or the CP. In Brown and Levinson the dimensions of Distance and Power are explicitly modeled, together with a dimension ranking acts as more or less imposing within a certain culture.
} 
interactional achievements not as the result of summative contributions by speech participants, but as co-constructed, discursive negotiations between them.

\section{Researching (im)politeness and indexicality}

To date, few studies apply an indexical approach to the analysis of (im)politeness phenomena in a systematic way (e.g. Errington 1988; Agha 1994, 1998; Irvine 1998), and these are all studies carried out by linguistic anthropologists. Moreover, the (im)politeness scholarship that does embrace an indexical approach tends to build on selected formulations in Ochs', Agha's and Silverstein's theorizations that have informed the development of third-wave variationist sociolinguistics (see Eckert, 2008). However, the influence of research on indexicality is gradually permeating into (im)politeness studies in many ways - some (for example, Holmes et al., 2012 and Hultgren, 2011) are increasingly adopting its vocabulary - , although not always fully consistently. This is not surprising, given the radically different view of language, and its workings, that the approach is predicated on. As noted above, it requires us to question long-held assumptions about meanings being "encoded" in linguistic forms, and instead requires us to fully engage with the idea that linguistic meaning is underdetermined by form; that meaning is actively construed by users, and that it emerges on the basis of any kind of available and relevant evidence (local and more global discourses, past and current events, linguistic and nonlinguistic contexts). Engaging with the notion of indexicality therefore represents a considerable paradigmatic shift. Correspondingly, the analysis of such, often volatile, circumstances constitutes a considerable methodological challenge.

\subsection{The social significance of indexicality in linguistic (im)politeness}

(Im)politeness theorists also have to contend with received wisdom specific to their field. The spread of the concept of wakimae (or 'discernment') is a case in point. Initially proposed in research on Japanese honorifics (Hill et al., 1986; Ide, 1989) as a principle regulating honorification arguably distinct from the principle (dubbed 'volitional') regulating polite strategies in English, the concept was readily adopted in other research on non-Western as well as Western languages, and the distinction legitimised and further propagated. Dissenting research has argued that the mechanisms regulating Japanese honorific or English propositional strategies (e.g. direct/indirect speech acts) are the same, 
as indeed both hinge on the interactional schema indexed by either honorific forms or other verbal strategies (Pizziconi, 2011). Recognising these indexical commonalities allows researchers to focus instead on the social significance, for language users, of differences in language affordances. This is not to be considered in the narrow sense of linguistic relativity (i.e. that 'language determines thought'), but in relation to the social consequences of such different affordances, for example for language socialization practices or metapragmatic discourses of politeness.

Burdelski (2013), for example, draws on the work of Silverstein, Ochs, and Agha to account for the broad range of social meanings that honorific usage by Japanese caregivers expose pre-school children to, and documents the extensive scaffolding ('prompting', 'speaking for') they adopt to encourage children's use of context-appropriate forms; it also notes that children appear to use honorific forms as indices of social identity or social roles at a very early age (3 years), possibly before they appreciate the (stereotypical) meaning of 'honorification' proper (and see Pizziconi, 2013, p. 150, for an account of further challenges that children face with other deictic properties of honorifics). Importantly, socialization to the use of politeness routines appears to be "multimodal”, involving talk as well as embodied actions, such as tactile guidance to encourage respectful bowing (Burdelski, 2011, p. 260), which inevitably builds up further cross-modal indexical associations. As noted by Agha (2007), cross-modal iconism "blurs the boundaries between language and non-language"; as a consequence, linguistic acts are perceived to be more or less felicitous depending on whether they appear congruent to other, non-linguistic or paralinguistic signs (2007, p. 22), including the posture, gaze, attire, etc. regularly associated with them. Adults' encouragements to bowing in Burdelski's study arguably aim to enhance the felicitousness of the child's performative act of "self-introduction".

The observation that users' interpretations of linguistic behaviour cannot be dissociated from webs of indexical associations demands an increased focus on various aspects of the users' reflexive activity (“activites in which communicative signs are used to typify other perceivable signs”, Agha 2007, p. 16), which provides evidence of linguistic ideologies. In an ethnographic study of honorific usage in Tongan 'chiefly language' (lea faka-'eiki) Philips's (2011) makes a call for an analysis of different aspects of language ideology, as they are revealed in metapragmatic comments. While reporting a generalized difficulty on the part of Tongan speakers in verbalising norms of honorific usage beyond the listing of broad categories of typical targets of deference, or in providing details of who uses which specific forms, Philips notes how her participants nevertheless produced 
elaborate explanatory narratives to account for instances of non-use ${ }^{12}$. These interpretive frames drew variably from ideologies regarding education, religion or politics and were closely linked to the participants' own local experiences. Some participants explain nonuse as a consequence of the speaker's father (a noble) having married a commoner, others imputed it to the speaker's overseas experience and westernization. Crucially, these indexical orders (and others) exist simultaneously (i.e. a speaker could variably use religion, schooling or exposure to overseas cultures to socially differentiate Tongans) and can be drawn on differentially, depending on the occasion of interaction.

In studies such as these we can recognise themes that have also emerged as concerns of recent (im)politeness research, especially the strand of studies on identity construction and 'relational work' (see Locher, 2008 for a review). Indexicality thus offers a rich paradigm to account for the semiotic multifunctionality of linguistic meaning, and its social, cultural, and fundamentally ideological embeddedness.

\subsection{Direct marking of (im)politeness vs. marking of stances, activities, identities}

The study of indexicality in language (and in particular its characterization of 'stereotypifications', the underdetermination of linguistic meaning and the ways in which context 'fleshes out' emergent interactional meanings, as noted in 2.2 and 2.3) has opened up, for (im)politeness theorists, a means of engaging with the full range of potential meanings that can be generated in interaction. Thus the analysis of forms that would previously be assumed to unproblematically presuppose deference, such as honorifics, or forms that would be assumed to be routinely associated to '(im)polite' manners (such as tag questions, hedges, indirect constructions, swearwords), reframed through the conceptual apparatus of indexicality studies, has begun to generate more nuanced accounts of the dynamics of signification and the contextual effects of these linguistic structures. Cook (2013), for instance, explains the (otherwise puzzling) variability observed in the use of referent honorification for the same participant during a single interactional exchange (and a single participation framework) as the evocation, or the very construction, of the dual participant identity of 'salesman' and 'scientist'. Both speaker and addressee are observed to orient to these different personae in the course of the exchange, and crucially,

\footnotetext{
12 These are said to respectively instantiate "normative” and "phenomenological” ideologies.
} 
they do so through recourse to the enregistered indexical associations implicit in honorific usage $^{13}$.

An increased interest in the construction of social personae (see also Blitvich and Sifianou in this volume) through variable usage of linguistic forms (honorific or otherwise) is what characterizes the so-called 'third wave' sociolinguistic variation studies (e.g. Eckert, 2008). These too draw inspiration from indexicality theory. An example that illustrates the influence of the third-wave variationist model is Sclafani's (2009) study, that explores the characterization of 'women's language' as an index of personhood. Sclafani analyses two televised parodies of American celebrity Martha Stewart, who she describes as being known as a prototypical Good Woman (“ingenious and successful in traditional homemaking enterprises like cooking, gardening, and craft making”), but later entangled in a widely publicized scandal which saw her indicted for insider trading and serving a fivemonth prison sentence (Sclafani, 2009, p. 106). Stewart's style in the parodies is rendered through elements indexically associated to a powerful ideological notion of femininity, such as (among other things) use of superpolite forms, hedges (e.g. if you like), empty adjectives (e.g. utterly fantastic), etc., (features listed in Lakoff's 1975 study on feminine language). Sclafani argues that the parodic effect is achieved through the juxtaposition of the viewers' knowledge of Stewart's 'behind-the-scenes Bad side' (p. 624) with the exaggeration ('iconizing') of linguistic features stereotypically associated with "Good Woman speech", some of which are deployed far more frequently than in the real Stewart's style. She also notes that previous analyses of style fail to capture the role of extra-linguistic behaviour in the achievement of a stylization and its parodic effects, as these signs too are part and parcel of users' knowledge of an indexical field.

A key premise in this, and other works in this tradition, is that the use of a linguistic resource (such as a tag question) does not directly index aspects of social identity captured by demographic categories such as 'female' or 'male' (or, for that matter, a specific interactional meaning such as 'politeness', as in Cook's work above, or Okamoto, 2004). Rather, within a specific cultural grouping, the social meanings that are typically indexed through the contextualised uses of a linguistic resource might be a stance (e.g.

\footnotetext{
${ }^{13}$ A similar argument is presented by Pizziconi (2009) on the function of various modal markers; assuming a direct link with honorification or 'facework' is maintained to be rather 'coarse', since this is only one of many interpretive possibilities, and not an invariable effect of the use of these markers. Rather, such linguistic forms must be seen to mark, at best, interactional stances: for example, epistemic uncertainty can be associated with a speaker reluctance to claim authority on a subject matter, and the contextual reading of the utterance may highlight the emergent meaning of unassuming 'humbleness'.
} 
authoritativeness, friendliness), which might in turn index a particular social role (see section 2.3) or a particular aspect of social identity, such as 'female'. Where such associations occur regularly, they are the result of 'stance accretion' (Eckert, 2008, p. 469). For example, a linguistic form that indexes sensitivity to another's face needs may indirectly index femininity if it occurs in a context that is informed by this particular ‘sedimentation’ (Hall \& Bucholtz, 2013, p. 125). Such associations (e.g. femininity with 'sensitive stances') are culturally-specific: there are examples, such as that provided in Ochs' work on the Malagasy in Madagascar, where it is men who are ideologically associated with this form of behaviour.

Irvine's (2001) indexical notion of style as a 'system of distinction' (cf. footnote 4) has percolated in various works, including Peterson \& Vaattovaara's (2014) analysis of the indexical fields of two Finnish lexical politeness markers: kiitos, the native politeness marker for 'thank you/please', and the loanword pliis. Through an online survey asking users' assessments of the type of person likely to use one or the other marker, as well as their reported likelihood of using these markers themselves, they discuss the distinctive styles these markers arguably index. While the native kiitos appears to have a wide distribution, and be likely to be used throughout Finland and by people of all ages, pliis appears to be consistently characterized as a marker distinctive of female speakers aged 20 or less in urban areas. More women than men (78\% vs. 41\%) also declare they are willing to use pliis but interestingly, more men claim they would be using pliis than all respondents consider men likely to use it - this appears to show a bias in the users' metapragmatic awareness (or their stereotypical ideologies of speakerhood). Finally, they propose that 'female user' is only a first order index of pliis, concluding that Pliis "instills a sense of positive politeness, at the same time bringing with it connotations of youth, urbanity, and, given its source as an English loanword, globalism” (p. 265). An exhaustive or categorical account of a linguistic form's indexical range is, therefore, theoretically impossible. The broad scope of an indexical field means that chains of associations can be generated which may feed into each other in a circular process, whose start and end is indistinguishable at any one time, discernible only over long-term processes of diachronic variation, when one of the other typification 'stabilises' as the dominant index, and it is used as departure point for further typifications.

\section{Case Study}


In this section we outline some of the aims, methods and findings of a study that has adopted an indexical approach to (im)politeness phenomena.

\section{Aims}

In her (2013) study of the indexical scope of strong swearwords, Christie locates her analysis within the indexical paradigm by claiming that it is designed to bring 'theorized order' (Silverstein, 2003, p. 194) to disparate phenomena that have been subject to analysis within different disciplines. Her point of departure is the often conflicting set of findings (and explanations of those findings) in studies that have addressed swearword use as a sociolinguistic variable, and in qualitative studies of swearwords as an (im)politeness resource $^{14}$ : the former linking the use of swear words to concepts such as covert prestige, which in turn is linked to masculinity; the latter linking the interpersonal and social effects of swearword use to specific contexts of use or conventionalised associations. Christie's aim in adopting an indexical approach to swearword use is to consider how the approach can account for both shared and individual attributions of social meaning to linguistic resources, and to show that it can do so without addressing individual attributions as nonce interpretations or as affirmations or rejections of the 'conventionalised' meanings attributed to linguistic formulae.

Culpeper, (2011, p. 129) building on Terkourafi's (2005) work, defines conventionalised (rather than conventional) meanings as those achieved when "particular expressions are associated in one's mind with particular contexts”. While accepting this definition, as well as Culpeper's (p. 124) proposal that regularities in the evaluation of (im)politeness formulae occur because they are constrained by the conventionalised associations that interlocutors share, Christie argues that, from an indexical perspective, such an account raises many further questions for (im)politeness research. She proposes that where there is evidence that a linguistic resource appears to have a conventionalised meaning, within an indexical paradigm this would function as a starting point, generating research questions such as: For whom do these specific associations exist? Do these associations exist for a specific person; a specific category of person; a community of practice; or a whole culture? Following Agha, Christie argues that in asking these questions, an indexical analysis of (im)politeness phenomena could include the following aims (a) to seek evidence, in the form of 'regularities of evaluative behaviour' by 'socially locatable persons' (Agha, 2003, p. 242 and section 2.3 above), that can be observed and

\footnotetext{
${ }^{14}$ Christie glosses (im)politeness resources as 'communicative resources that are subject to (im)politeness evaluations' (Christie, 2013 p.153)
} 
documented in support of any claim that specific conventional associations are being activated in the interpretation of linguistic formulae (2013, p. 155); (b) to identify and articulate the ideologies informing such associations; and (c) to explore the extent to which alternative associations are documented.

\section{Method}

Christie's study follows the trajectory mapped out above by first identifying the conventionalised association between the use of strong swearwords and particular contexts of use. She shows that sociolinguistic studies as well as corpus analyses provide documented evidence of a link between male working-class speakers and strong swearwords. Her point is that, although this association would be taken as self-evident for most native speakers of British English, it is necessary to start from documented evidence of that link if the ideologies that this first-order association generates (see section 2.3) are to be understood. In continuing to follow the trajectory of the indexical method further, Christie builds on Eckert's proposal that a first-order index simply indexes membership of a population, but that once a form that has acquired an indexical value it can always be reinterpreted so that it acquires "an $n+1$ st value” (2008, p. 463, in turn building on Silverstein 2003): if strong swearwords index membership of the population of British working-class males, this will be the basis upon which the use of strong swearwords are able to index a wider range of social meanings. The second stage of her analysis therefore charts the scope of the social meanings (i.e. their indexical field) through the active assignment of cultural values to swearwords in newspaper reports that comment on public uses of strong swearwords. However, Christie also argues that the sociolinguistic approach does not address the processes by which indexing is achieved. Her analysis therefore extends the sociolinguistic model by addressing metapragmatic discourse (see section 3) from a relevance theoretic perspective, showing how the explicatures, implicated premises and contextual implications generated by newspaper commentary can bring into view ideologies of class and gender that derive from the first-order index.

\section{Sample Analysis}

The following is an example of a newspaper report in which Christie identifies ideologies of class that justify swearword use by the footballer Wayne Rooney by relating it to the Football Association's previous acceptance of this behaviour: 
In May 2005, in one match with Arsenal alone, he [Rooney] was caught swearing at referee Graham Poll at least 20 times. The FA did not act, despite the incident being highlighted, because they understand the football field to be a workplace and industrial language part of its currency. (Daily Mail April 27, 2011)

Focusing on the italicised element of the extract, Christie argues that the cultural evaluation of swearing evident in this report indicates that swearing is justified in certain circumstances. She also argues that, in British culture, working out what those circumstances are requires the reader to be able to link a particular type of workplace and a particular type of worker to the use of swearing: i.e. industrial rather than office workplaces; and working class rather than middle class workers. Her analysis shows how the application of relevance theory can account for such an interpretation.

In the analysis, Christie identifies key presuppositions (which within relevance theory would be categorised as implicated premises) that a reader must activate in order to arrive at the above interpretation of the italicised element of the extract. These include:

(a) the football field is a workplace setting

(b) swearing always occurs in workplace settings.

Christie also draws on relevance theory to argue that certain 'explicitly' communicated elements must be pragmatically modified if the statement in the italicised section is to generate relevant propositions: the term workplace must be narrowed to signify 'working class, industrial workplaces' (e.g. rather than offices or shops); and the term industrial language must be narrowed to signify 'swearing'.

In arguing that the extract implies that swearing is to be expected on the football field, Christie's analysis shows that this implication is enabled by ideologies of class: if the football field is a working class, industrial workplace and swearing always occurs in such workplaces, then swearing will occur on the football field. This is seen to be a relevant interpretation of the italicised elements in the context of the remainder of the article because it explains why the Football Association had not responded to Rooney's previous swearword use. The report therefore provides a justification of Rooney's use of swearwords by associating it with working class behaviour.

\section{Findings}

Christie's analysis of further examples of metapragmatic commentary shows that recurring ideological assumptions about gender and class are activated in the rationalisation of acts of swearing. These ideological assumptions are evident in the metapragmatic commentary 
whether the acts are evaluated as justified (such as above) or as unjustified and therefore subject to negative evaluation. She also shows that all swearword use is regularly measured against the characteristics of justified uses, which demonstrates that the social meanings attributed to swearword use are enabled and constrained by the ideologies that inform the metapragmatic commentary. Christie's further analyses show, for example, that swearword use is only able to index positive stances if it is evaluated as justified because a speaker is responding to emotion or if it is ratified by an aspect of social identity (i.e. the speaker is male and working class). Her analyses of the metapragmatic commentaries also show that, since this is the basis of the evaluation, women - and particularly middle-class women - who use strong swearwords tend to be judged as carrying out 'inauthentic' acts. The following extract from a report on a female celebrity's use of a strong swearword on a television programme illustrates this:

Gwynnie, I swear you're a foul-mouthed old phoney: there seemed to be something curiously staged about the incident (Mail on Sunday May 1, 2011)

Christie's findings suggest that when evaluated in the context of apparently justified uses of swearwords (i.e. emotionally or situationally justified uses by male working class speakers) women's use of swearwords is often found to be unjustified. Her findings show therefore that the conventionalised meanings associated with swearword use are documented (and therefore) perpetuated in public iterations of ideologically informed evaluations of acts of swearing. She points out that although it would be possible to chart alternative evaluations of swearword use in other metapragmatic commentaries commentary, the specific evaluations set out in the news reports that she analysed suggest that these ideologies constrain the indexical scope of swearword use: according to that metapragmatic discourse, it is possible for men, but not women, to index a stance such as 'authenticity' through the use of strong swearwords.

\section{Summary/conclusions}

Studying (im)politeness from an indexical perspective requires an engagement with context above and beyond generic statements that 'contexts affects meaning'. Meaning is affected by local and volatile contexts of interaction because is it not encoded in linguistic forms but 'emerges' from the interaction of linguistic forms with co-textual and contextual signs. Meaning is also affected by broader diachronic or synchronic contexts, such as 
historical contexts (accretions of particular indexical associations over time) or large sociocultural contexts (the multiple indexical orders in which the same sign receives different valorizations). While the latter can account for constraints that contexts can exercise on speaker choices - through the particular landscape of recognisable registers available to speakers - the former can illustrate and explicate instances of speaker 'creativity', and the processes that enable the generation, or 'constitution', of novel meanings. For this reason, studying (im)politeness as an indexical phenomenon requires a programmatic engagement with authentic, situated data, such as actual occasions of utterance or observable evidence of metadiscourses about (im)polite behaviour, as well as an account of the broader cultural and historical background against which these occur.

As noted in the beginning of this chapter, pragmatically as well as ethnographically inspired accounts are necessary to investigate the different facets of (im)politeness as an indexical phenomenon. Honorific forms, often characterised as "social deictics", have obvious structuring properties, i.e. they can schematize patterns of participant role; this feature is shared with other forms (e.g. pronouns, or speech acts), and pragmatic accounts can illustrate how these properties are relied upon in the characterization of social activities (for example, actions that are carried out 'humbly' or non-coercively); other non-honorific or non-deictic forms, as linguistic features recognised as components of specific registers, carry additional information on the social positioning of such participants, and ethnographic accounts can illustrate how these forms participate in membership categorization (for example, 'educated', 'refined', 'authoritative' speaker types). Social evaluations, of which (im)politeness is but one type, have a central position within an indexical framework, as evidence of the distinct ideologies shaping different valorizations of linguistic and non-linguistic behaviour; the characterization of a linguistic form as 'justified' or 'proper' (as opposed to 'inauthentic' or 'rude', 'typical' or 'parodic'), is dependent on speakers' ideological 'take' on how people should, or are expected to speak, and in which circumstances.

Recent research on (im)politeness has begun to interrogate some of these issues (the 'emergent' nature of some social meanings, the role of ideologies in interpretation, and the social instrumentality of (im)politeness). Further research may benefit from other observations brought into view in an indexical approach: the need to support claims about conventional associations with some sort of empirical evidence; the need to address (and identify) documented evidence of ideology when making claims about meaning; the need 
to consider the significance of the mediating elements (stance, style) between an index and social identity before attempting generalisations about patterns of indexing.

Many other issues germane to indexicality remain under-researched, at least within the dedicated field of (im)politeness studies. Future research could explore further other semiotic systems which co-exist with linguistic (im)politeness (e.g. etiquette, rituals, or other cultural practices), or pursue documented accounts of systematic 'violations' of canonical usages which have generated significant shifts in the meaning of (im)polite forms. Much is left to explore regarding processes of typification (or 'essentialization') or the dynamics of '(mis)alignment' in adult second language learning.

\section{References}

Agha, A., (1994). Honorification. Annual Review of Anthropology 23, 277-302.

Agha, A., (1998). Stereotypes and registers of honorific language. Language in Society 27 (2), 151-193.

Agha, A. (2003). The Social Life of Cultural Value. Language \& Communication 23, 231273.

Agha, A. (2007). Language and social relations. Cambridge:Cambridge University Press.

Bargiela Chiappini, F. \& Kádár, D. Z. (eds.). (2011). Politeness across Cultures. Basingstoke, England: Palgrave Macmillan.

Blommaert, J. (2007). Sociolinguistics and discourse analysis: orders of indexicality and polycentricity, Journal of multicultural discourses 2, 115-130.

Brown, L. (2011). Korean Honorifics and Politeness in Second Language Learning. Amsterdam: John Benjamins.

Brown, R. \& Gilman, A. (1960). The pronouns of power and solidarity. In Sebeok, T. A. (ed.), Style in Language, Cambridge: MIT press. 253-76.

Brown, P. \& Levinson, S. C. (1987 [1978]). Politeness. Some universals in language usage. Cambridge: Cambridge University Press.

Buchotlz, M. (2009). From Stance to Style: Gender, Interaction, and Indexicality in Mexican Immigrant Youth Slang. In A. Jaffe (ed.), Stance: Sociolinguistic Perspectives (pp. 146-170). New York: Oxford University Press.

Burdelski, M. (2011). Language socialization and politeness routines. In A. Duranti, E. Ochs, \& B. B. Schieffelin (Eds.), The handbook of language socialization (pp. 275295). Malden, MA: Wiley-Blackwell.

Burdelski, M., (2013). Socializing children to honorifics in Japanese: Identity and stance in interaction. Multilingua, 32(2): 247-273.

Christie, C. (2007). Relevance theory and politeness. Journal of Politeness Research 3, 269-294.

Christie, C. (2013). The relevance of taboo language: An analysis of the indexical values of swearwords. In Journal of Pragmatics 58,152-169.

Cook, H. Minegishi. (2013). A scientist or salesman? Identity construction through honorifics on a Japanese shopping channel program. Multilingua 23(2), 177-202. 
Culpeper, J. (2011). Impoliteness: Using Language to Cause Offence. Cambridge: Cambridge University Press.

Culpeper, J. \& Demmen, J. (2011). Nineteenth-century English politeness: Negative politeness, conventional indirect requests and the rise of the individual self. In: Journal of Historical Pragmatics. 12 (1-2), 49-81.

Duranti, A. (1993). Truth and intentionality: an ethnographic critique. Cultural Anthropology, 8, 214-245.

Eckert, P. (2004). The Good Woman. In M. Bucholtz (Ed.) Language and a Woman's Place: Text and Commentaries (pp. 165-170). Oxford: Oxford University Press.

Eckert, P. (2008). Variation and the indexical field. Journal of Sociolinguistics 12, 453476.

Eelen, G. A. (2001). Critique of Politeness Theories. Manchester: St. Jerome Publishing.

Errington, J. J. (1988) Structure and Style in Javanese: A Semiotic View of Linguistic Etiquette. Philadelphia: University of Pennsylvania Press.

Fillmore, C. J. (1997). Lectures on deixis. Stanford, CSLI Publications.

Graham, S. (2007). Disagreeing to Agree: Conflict (Im)politeness and Identity in a Computer-Mediated Community. Spencer-Oatey, H. and Ruhi, S. (Eds.), Journal of Pragmatics 39(4), 742-759.

Hall, K. \& Bucholtz, M. (2013). Epilogue: Facing Identity. Journal of Politeness Research 9, 123-132.

Hanks, W. F. (2000). Intertexts, Writings on Language, Utterance and Context. Denver: Rowman and Littlefield.

Hanks, W. (2009). Fieldwork on deixis. Journal of Pragmatics 41, 10-24.

Hill, B.; Ide, S., Ikuta, S., Kawasaki, A. \& Ogino, T. (1986). Universals of linguistic politeness. Quantitative evidence from Japanese and American English. Journal of Pragmatics 10, 347-471.

Hiraga, M. K. (1999). DEFERENCE as DISTANCE: Metaphorical base of honorific verb construction in Japanese. In M. K. Hiraga, Sinha C. \& Wilcox, S. (Eds). Cultural, Psychological and Typological Issues in Cognitive Linguistics, (pp. 47-68). Amsterdam: John Benjamins.

Holmes, J., Marra, M., \& Vine, B. (2012). Politeness and impoliteness in ethnic varieties of New Zealand English. Journal of Pragmatics, 44 (9), 1063-1076.

Hultgren, A. K. (2011). Building rapport' with customers across the world: The global diffusion of a call centre speech style. Journal of Sociolinguistics, 15(1), 36-64.

Irvine, J. T. (2001). 'Style' as distinctiveness: The culture and ideology of linguistic differentiation. In J. R. Rickford \& Eckert P. (eds.) Style and Sociolinguistic Variation (pp. 21-43). New York/Cambridge, U.K.: Cambridge University Press.

Irvine,J. T. (1998). Ideologies of Honorific Language. In Schieffelin, Bambi B., Woolard, K. A., Kroskrity, P. V. (Eds), Language Ideologies : Practice and Theory (pp. 5167), New York: Oxford University Press.

Lakoff, R. T. (1973). The logic of politeness, or minding your p's and q's. Chicago Linguistics Society, 9, 292-305.

Lakoff, R. (1975). Language and Woman's Place. New York: Harper \& Row.

Leech, G.. (1983). Principles of Pragmatics. New York: Longman.

Levinson, S. C. (1983). Pragmatics. Cambridge: Cambridge University Press.

Levinson, S. C. (2004). Deixis. In L. R. Horn \& Ward G. L. (Eds.). The handbook of pragmatics, (pp. 97-121). Malden, MA: Blackwell.

Locher, M. A. (2004). Power and politeness in action: Disagreements in oral communication. Berlin: Mouton de Gruyter. 
Locher, M. A. (2008) Relational work, politeness and identity construction. In G. Antos, E. Ventola and T. Weber (Eds.), Handbooks of Applied Linguistics. Volume 2: Interpersonal Communication, (pp. 509-540). Berlin: Mouton de Gruyter.

Locher, M. A. (2012). Politeness research from past to future, with a special focus on the discursive approach. In L. Fernández-Amaya, de la O Hernández López M., Gómez Morón R., Padilla Cruz, M., Mejias Borrero M. \& Relinque Barranca M. (Eds.), New perspectives on (im)politeness and interpersonal communication, (pp. 36-60). Newcastle: Cambridge Scholars.

Locher, M.A., and Watts, R.J. (2008). Relational work and impoliteness: Negotiating norms of linguistic behaviour. In D. Bousfield and M. A. Locher (Eds.), Impoliteness in language. Studies on its interplay with power in theory and practice, (pp. 77-99). Berlin: Mouton de Gruyter.

Lyons, J. (1977). Semantics, vol 1 \& 2. Cambridge: Cambridge University Press.

Marmaridou, S. A. (2000). Pragmatic Meaning and Cognition. Amsterdam/ Philadelphia: John Benjamins.

Martin, S. (1964). Speech Levels in Japan and Korea. In Hymes, D. (Ed.), Language in Culture and Society (pp. 407-415). Harper and Row, New York.

Mills, S. (2003). Gender and politeness. Cambridge: Cambridge University Press.

Mills, S. (2005) Gender and impoliteness. Journal of Politeness Research 1 (2), 263-280.

Mills, S.. (2011). Discursive approaches to politeness and impoliteness. In Linguistic Politeness Research Group (Eds.), Discursive approaches to politeness (p. 19-56). Berlin: Mouton de Gruyter.

Moore, E. and R. Podesva. (2009). Style, indexicality and the social meaning of ta questions. Language in Society 38, 447-485.

Ochs, E. (1993). Indexing gender. In Miller, B. D. (ed.), Sex and Gender Hierarchies. New York: Cambridge University Press.

Ochs, E. (1996). Linguistic Resources for Socializing Humanity. In Gumperz J. \& Levinson S. (Eds.), Rethinking linguistic relativity, (pp. 407-438). Cambridge: Cambridge University Press.

Okamoto, S. (2004). Ideology in Linguistic Practice and Analysis. Gender and Politeness in Japanese Revisited. In: Okamoto, S. \& Shibamoto-Smith, J. S. (Eds.), Japanese Language, Gender, and Ideology. Cultural Models and Real People, (pp. 38-56). Oxford University Press, Oxford.

Peterson, E., \& Vaattovaara, J. (2014). Kiitos and pliis: The relationship of native and borrowed politeness markers in Finnish. Journal of Politeness Research, 10 (2), 247-269.

Peirce, C. S. ([1894] 1998). What is a sign?. In N. Houser, Eller, J. R., Lewis, A. C., De Tienne, A., Clark, C. L. \& Davis D. B. (Eds. ), Essential Peirce Volume 2: Selected Philosophical Writings, 1893-1913, Peirce Edition Project, and ebrary Academic Complete. Bloomington: Indiana University Press. [Electronic version accessed 17 October 2015]

Peirce, C. S. ([1895] 1998). Of reasoning in general. In N. Houser, Eller, J. R., Lewis, A. C., De Tienne, A., Clark, C. L. \& Davis D. B. (Eds. ), Essential Peirce Volume 2: Selected Philosophical Writings, 1893-1913, Peirce Edition Project, and ebrary Academic Complete. Bloomington: Indiana University Press. [Electronic version accessed 17 October 2015]

Peirce, C. S. 1901. Index (in exact logic). In J.M. Baldwin (Ed.), Dictionary of Philosophy and Psychology Volume One, (pp. 531-532). London: Macmillan and Co.

Philips, S. U. (2011) How Tongans Make Sense of the (Non-) Use of Lexical Honorifics. Journal of Linguistic Anthropology 21 (2), 247-260. 
Pizziconi, B. (2009). The interactional consequences of epistemic deixis - some thoughts on the epistemic marker -kamoshirenai, in B. Pizziconi \& Kizu, M (eds.), Japanese Modality (pp. 259-286). Basingstoke, England: Palgrave.

Pizziconi, B. (2011). Japanese honorifics: the cultural specificity of a universal mechanism. In S. Mills \& Kádár D. Z. (Eds.), Politeness in East Asia - Theory and Practice, (pp. 45-70). Cambridge: Cambridge University Press.

Pizziconi, B. (2013). Introduction. Multilingua, 32(2), 247-273.

Pizziconi, B. (forthcoming) Social deixis: honorifics and polite speech, Handbook of Japanese Semantics and Pragmatics, Mouton Handbooks on Japanese Language and Linguistics, (VI) 1, Mouton de Gruyter.

Ponzio, A. (2006). Indexicality: theory. In K. Brown (Ed.), Encyclopaedia of Language and Linguistics, Boston: Elsevier, 596-603.

Sclafani, J. (2009). Martha Stewart behaving badly: Parody and the symbolic meaning of style. Journal of Sociolinguistics, 13 (5), 613-633.

Shibatani M. (1990). The Languages of Japan. Cambridge: Cambridge University Press.

Sifianou, M. (2010). Linguistic politeness: Laying the foundations. In Locher M. A. \& Graham, S. L. (Eds.), Interpersonal pragmatics, (pp. 17-41). Berlin: Mouton de Gruyter.

Silverstein M. (1976). Shifters, verbal categories and cultural description. In Basso K. \& Selby H. (Eds.) Meaning in anthropology (pp. 11-57). Albuquerque: School of American Research.

Silverstein M. (2003). Indexical order and the dialectics of sociolinguistic life. Language and Communication 23:193-229.

Silverstein, M. (2010). "Direct" and "indirect" communicative acts in semiotic perspective. Journal of Pragmatics 42, 337-353.

Snell, J. 2010. From sociolinguistic variation to socially strategic stylization. Journal of Sociolinguistics (14/15), 630-656.

Terkourafi, M. (2005). Beyond the micro-level in politeness research. Journal of Politeness Research 1:2, 237-262.

Verschueren, J. (2000). Notes on the role metapragmatic awareness in language use. Pragmatics 1:439-456.

Watts, R. J. (2003). Politeness. Cambridge: Cambridge University Press.

Watts, R. J, Ide S. \& Ehlich K. (eds.) (1992). Politeness in language: studies in its history, theory and practice. Berlin: Mouton de Gruyter.

Woolard, K. A. (1998). Introduction: Language ideology as a field of Inquiry. In Schieffelin, Bambi B., Woolard, K. A., Kroskrity, P. V. (Eds), Language Ideologies : Practice and Theory (pp. 3-47), New York: Oxford University Press. 